\title{
Dithienylbenzothiadiazole Based Donor-acceptor Organic Semiconductors and Effect of End Capping Groups on Organic Field Effect Transistor (OFET) Performance
}

\author{
Prashant Sonar ${ }^{1 *}$, Samarendra P. Singh ${ }^{1,3}$, Ting Ting $\operatorname{Lin}^{1}$, Ananth Dodabalapur ${ }^{1,2^{*}}$ \\ 1. Institute of Materials Research and Engineering, 3 Research Link Singapore 117602, Republic of \\ Singapore.
}

2. Permanent Address: Microelectronics Research Center, The University of Texas at Austin, Austin, TX, 78758, USA.

3. Present Address: Shiv Nadar University, Greater Noida, India.

sonarp@imre.a-star.edu.sg, ananth.dodabalapur@engr.utexas.edu

\begin{abstract}
Donor-Acceptor-Donor (D-A-D) based conjugated molecules 4,7-bis(5-(4-butoxyphenyl)thiophen-2yl)benzo[c][1,2,5]thiadiazole (BOP-TBT) and 4,7-bis(5-(4-trifluoromethly)phenyl)thiophen-2yl)benzo[c][1,2,5]thiadiazole (TFP-TBT) using thiophene-benzothiadiazole-thiophene central core with trifluoromethyl phenyl and butoxy phenyl end capping groups were designed and synthesized respectively via Suzuki coupling. Optical, electrochemical, thermal, and organic field effect transistors (OFET) device properties of BOP-TBT and TFP-TBT were investigated. Both small molecules possess two absorption bands. Optical band gaps were calculated from the absorption cut off and which yields values in the range of 2.06-2.25 eV. Cyclic voltammetry indicated reversible oxidation and reduction processes and the highest occupied molecular orbital (HOMO) and the lowest unoccupied molecular orbital (LUMO) energy levels were calculated to be in the range of $5.15-5.40 \mathrm{eV}$ to $3.25 .-3.62 \mathrm{eV}$ respectively. Upon testing both materials for OFET, trifloromethyl phenyl end capped material (TFP-TBT) shows n-channel whereas butoxy phenyl end capped material (BOP-TBT) shows p-channel behavior. DFT calculations correlated with shifting of HOMO-LUMO with respect to end capping groups are discussed in detail. Vacuum processed OFETs of these materials have shown highest hole carrier mobility of $0.02 \mathrm{~cm}^{2} / \mathrm{Vs}$ and electron carrier mobility of $0.004 \mathrm{~cm}^{2} / \mathrm{Vs}$, respectively using $\mathrm{Si} / \mathrm{SiO}_{2}$ substrate. By keeping similar central D-A-D conjugated segment and just by tuning end capping groups gives both $\mathrm{p}$ - and $\mathrm{n}$ - channel organic semiconductors can be prepared in a single step using straightforward synthesis.
\end{abstract}

Corresponding author: sonarp@imre.a-star.edu.sg, Institute of Materials Research and Engineering (IMRE), Agency for Science, Technology and Research (A*STAR), 3 Research Link, Republic of Singapore 117602, Fax: +65-68727528, Tel: +6568727534 


\section{Introduction}

Organic field effect transistors (OFETs) using small molecule organic semiconductors have received great attention due to their potential applications in low cost organic electronics. ${ }^{1-4}$ OFETs using organic semiconductors can potentially be utilized in applications such as drivers for large-area flexible displays or low end data storage smart cards. Organic materials possess the advantages of easy tuning of chemical structures, simpler processing and proven compatibility with plastic substrates. Additionally, their optoelectronic properties can be tuned easily by selecting appropriate conjugated building blocks in the backbone. Using such blocks, a library of both electron donor (hole transporting) and electron acceptor (electron transporting) materials with high thermal/chemical stability, facile processability, high charge carrier mobility, and controllable highest occupied molecular orbital (HOMO) and the lowest unoccupied molecular orbital (LUMO) energy levels can be prepared. ${ }^{5-20}$ Among reported hole transporting and electron transporting materials, $\pi$-conjugated small molecules are an important category of organic semiconductors due to their well defined, monodisperse, discrete structure with synthetic reproducibility. ${ }^{21-}$

${ }^{26}$ Small molecules are easier to purify and therefore result in less batch-to-batch variation. Small molecules have been studied extensively for OFET applications and amongst the most important materials classes are oligoacene and oligothiophene derivatives. Among all these materials, recently donor-acceptor-donor (D-AD) based small molecules are becoming attractive candidates for OFET applications due to their strong intramolecular interactions. ${ }^{27}$ Additionally, due to donor-acceptor charge transfer and low band gap, these materials also have been used successfully as a donor component in organic photovoltaics (OPV). ${ }^{28,29}$ The widely studied D-A-D based materials are mostly related with thiophene (D) and benzothiadiazole (A) building blocks due to their $-\mathrm{i}$ ) easy availability, ii) several possibilities of structural modification, iii) straightforward synthesis and iv) promising performance in organic electronic devices. The thiophenebenzothiadiazole conjugated system also has a benefit of forming self-assembled molecular assemblies in the solid state due to sulfur - nitrogen $(\mathrm{S}-\mathrm{N})$ interactions ${ }^{27}$. Such intramolecular and intermolecular interactions through $\pi-\pi$ stacking are expected to provide a good charge transportation pathway. Yamashita et al have reported several such classes of functional materials for $\mathrm{p}$ - and n-channel OFET applications. ${ }^{27}$ Our group has been also working on such class of D-A-D based materials since last few years and trying to understand the structure-property relationship of these materials through fine tuning in the structural design and its effect on various optoelectronic properties (absorption, emission, energy level tuning, morphology and charge transport behavior). ${ }^{30-32}$ These materials have been successfully used in as active layers in OFET and organic photovoltaics (OPV) devices. In this work, we are reporting design and synthesis of two D-A-D based materials 4,7-bis(5-(4-butoxyphenyl)thiophen-2yl)benzo[c][1,2,5]thiadiazole (BOP-TBT) and 4,7-bis(5-(4-trifluoromethly)phenyl)thiophen-2yl)benzo $[c][1,2,5]$ thiadiazole (TFP-TBT) ${ }^{33,34}$ Though the synthesis of both compounds have been reported previously but there is no systematic comparison of both materials in terms of various properties (optical, electrochemical, thermal and electrical) and their comparative performance in OFETs. Both D-A-D 
materials have a similar conjugated backbone except for the difference in end capping groups. The rationale behind using alkoxy and trifluoromethyl substituted phenylene end capping groups for synthesizing these D-A-D materials is to check the effect of electron donating and electron accepting end groups on its optical, electrochemical and charge transport properties. These materials were characterized by various tools such as MALDI-TOF, absorption and emission spectroscopy, cyclic voltammetry (CV), thermogrvimetric analysis (TGA), differential scanning calorimetry (DSC) and by theoretical modeling. OFETs made from BOP-TBT using vacuum deposition on octyltrichlorosilane (OTS) treated $\mathrm{Si} / \mathrm{SiO}_{2}$ substrate exhibited a hole mobility of $2 \times 10^{-2} \mathrm{~cm}^{2} / \mathrm{Vs}$ whereas TFP-TBT deposited devices exhibited an electron mobility of $4 \times 10^{-3} \mathrm{~cm}^{2} / \mathrm{Vs}$ with gold source and drain electrodes. We demonstrated that by using the different end capping groups with similar D-A-D conjugated, we can create both p-channel and nchannel organic semiconductors with minimal synthesis efforts. Due to high hole and electron mobility and low band gap, these materials are also potential candidates for bilayer OPV devices. The detailed synthesis, characterization, and effect of end capping group on device performance are discussed below.

\section{Experimental Part}

\subsection{Materials}

All commercially available materials [(4-butoxyphenyl) boronic acid, 4-(trifluoromethyl)phenyl)boronic acid, tetrakis(triphenylphopshine)] were used as received unless otherwise noted. 4, 7-bis(5bromothiophene-2-yl) benzothiadiazole was synthesized according to published procedure. ${ }^{35}$ All reactions were carried out using Schlenk techniques under an argon or nitrogen atmosphere in anhydrous solvents.

\subsection{Synthesis}

2.2.1 4,7-bis(5-(4-butoxyphenyl)thiophen-2-yl)benzo $[c][1,2,5]$ thiadiazole (BOP-TBT): To a Schlenk flask 4-(butoxyphenyl) boronic acid (0.425 g, $2.19 \mathrm{mmol})$ and 4, 7-bis(5-bromothiophene-2-yl) benzothiadiazole $(0.400 \mathrm{~g}, 0.87 \mathrm{mmol})$, potassium carbonate $\left(\mathrm{K}_{2} \mathrm{CO}_{3}\right)(7 \mathrm{ml}, 2 \mathrm{M}$ aqueous solution) and $3 \mathrm{~mL}$ of ethanol were dissolved in toluene $(15 \mathrm{~mL})$. The solution was purged with argon for $30 \mathrm{~min}$, and then tetrakis (triphenylphosphine) palladium (20 mg, $0.017 \mathrm{mmol}$ ) was added instantly under argon flow. The reaction mixture was freeze-pump thaw cycled three times and then stirred at $80^{\circ} \mathrm{C}$ for $48 \mathrm{~h}$ under argon. After completion of the reaction, toluene was removed and the product was precipitated in methanol, the resulting solid was filtered off and washed with copious amount of methanol. The crude product was purified using vacuum train sublimation at high temperature (250 to 300 degree Celsius) yielding the pure product as dark red crystalline needles (yield 77\%). Due to less solubility of the material we could not able to measure the NMR spectra. We confirmed the purity of the compound using elemental analysis and MALDI-TOF techniques. 
Elemental Analysis Calculated for $\mathrm{C}_{34} \mathrm{H}_{32} \mathrm{~N}_{2} \mathrm{O}_{2} \mathrm{~S}_{3}$ (theorotical): C 68.42, H 5.40, N 4.69, O 5.36, S $16.12 \%$; Elemental Analysis Obtained for $\mathrm{C}_{34} \mathrm{H}_{32} \mathrm{~N}_{2} \mathrm{O}_{2} \mathrm{~S}_{3}$ (experimental): C 68.43, H 5.16, N 4.56, S $15.98 \%$. MS (MALDI-TOF, $m / z$ ): found 596.26; calcd. for $\mathrm{C}_{34} \mathrm{H}_{32} \mathrm{~N}_{2} \mathrm{O}_{2} \mathrm{~S}_{3}=596.16$.

\subsubsection{4,7-bis(5-(4-trifluoromethly)phenyl)thiophen-2-yl)benzo[c][1,2,5]thiadiazole (TFP-TBT)}

4-Trifluoromethyl)phenyl)boronic acid (0.500 g, $2.50 \mathrm{mmol})$ and 4, 7-bis(5-bromothiophene-2-yl) benzothiadiazole $(0.500 \mathrm{~g}, 1.09 \mathrm{mmol})$, sodium hydroxide $(\mathrm{NaOH})(5 \mathrm{ml}, 2 \mathrm{M}$ aqueous solution) were added to a Schlenk flask and then dissolved in toluene $(30 \mathrm{~mL})$. The solution was purged with argon for 30 $\mathrm{min}$, and then tetrakis (triphenylphosphine) palladium $(150 \mathrm{mg}, 0.12 \mathrm{mmol}$ ) was added quickly under argon flow. The reaction mixture was freeze-pump thaw cycled three times and then stirred at $80^{\circ} \mathrm{C}$ for $48 \mathrm{~h}$ under argon. After completion of the reaction, toluene was removed and the product was precipitated in methanol, the resulting solid was filtered off and washed with copious amount of methanol. The crude product was purified using vacuum train sublimation at high temperature (250 to 300 degree Celsius) yielding the pure product as dark red crystalline solid (yield 61\%). Again due to limited solubility of this material we could not perform NMR spectroscopy. Purity of the compound was confirmed by the elemental analysis and MALDI-TOF techniques.

Elemental Analysis Calculated for $\mathrm{C}_{28} \mathrm{H}_{14} \mathrm{~F}_{6} \mathrm{~N}_{2} \mathrm{~S}_{3}$ (theorotical): C 57.13, H 2.40, F, 19.37, N 4.76, S 16.34 $\%$; Elemental Analysis Obtained for (experimental): C 56.98, H 2.18, N 4.62, S $15.73 \%$. MS (MALDITOF, $m / z$ ): found 588.10; calcd. for $\mathrm{C}_{28} \mathrm{H}_{14} \mathrm{~F}_{6} \mathrm{~N}_{2} \mathrm{~S}_{3}=588.02$

\subsection{Characterization and Measurements}

Matrix-assisted laser desorption ionization time-of-flight (MALDI-TOF) mass spectra were obtained on a Bruker Autoflex TOF/TOF instrument using dithranol as the matrix. Elemental analysis was conducted on a CHNSO Elemental Analyzer for quantitative measurements using FLASH EA-112 series by Themro Electron Corporation. UV-Vis spectra were recorded on a Shimadzu model 2501-PC. Differential scanning calorimetry (DSC) was carried out under nitrogen on a TA Instrument DSC Q100 with a scanning rate of $10{ }^{\circ} \mathrm{C} \mathrm{min}^{-1}$. Thermal gravimetric analysis (TGA) was carried out using a TA Instrument TGA Q500 and a heating rate of $10{ }^{\circ} \mathrm{C} \mathrm{min}^{-1}$. Cyclic voltammetry experiments were performed using an Autolab potentiostat (model PGSTAT30) by Echochimie. Measurements were recorded in dichloromethane solutions of BOPTBT and TFP-TBT under argon at room temperature with a conventional three-electrode arrangement consisting of a platinum wire working electrode, a gold counter electrode, and an $\mathrm{Ag} / \mathrm{AgCl}$ in $3 \mathrm{M} \mathrm{KCl}$ reference electrode, respectively. HOMO values were calculated from the corresponding oxidation onsets 
which were converted to SCE (saturated calomel electrode), based on an $-4.4 \mathrm{eV}$ SCE energy level relative to vacuum using IP $=-\left(\mathrm{E}_{\text {ox-onset }}+4.4\right) \mathrm{eV}$. Likewise, $\mathrm{LUMO}$ levels were obtained from the reduction onsets via $\mathrm{EA}=-\left(\mathrm{E}_{\text {red-onset }}+4.4\right) \mathrm{eV}$.

\subsection{OFET Fabrication and Characterization:}

Top contact/bottom gate OFET devices were fabricated using $\mathrm{n}^{+}-\mathrm{Si} / \mathrm{SiO}_{2}$ substrates where $\mathrm{n}^{+}-\mathrm{Si}$ and $\mathrm{SiO}_{2}$ work as gate electrode and gate dielectric, respectively. Substrates were cleaned using ultrasonication in acetone, methanol and de-ionized water consequently. The cleaned substrates were dried under a nitrogen flow and heated at $100{ }^{\circ} \mathrm{C}$ for $5 \mathrm{~min}$. The substrates were then treated in UV-ozone for $20 \mathrm{~min}$. Then, the substrate was kept in a desiccator with a few drops of octyltrichlorosilane (OTS). The desiccator was evacuated for $3 \mathrm{~min}$ and placed in an oven at $110{ }^{\circ} \mathrm{C}$ for $3 \mathrm{hr}$. The substrate was removed from the desiccator, thoroughly rinsed with isopropanol, and dried under a nitrogen flow. For all sets of OFETs, thin films of BOP-TBT and TFP-TBT were vacuum deposited on OTS treated $\mathrm{Si} / \mathrm{SiO}_{2}$ substrates. Patterned gold layers of thickness $\sim 100 \mathrm{~nm}$ were deposited for use as source (S) and drain (D) electrodes through a shadow mask. For typical OFET devices reported here, the source-drain channel length (L) and channel width (W) were $100 \mu \mathrm{m}$ and $1 \mathrm{~mm}$, respectively. The device characteristics of the OFETs were measured at room temperature under nitrogen with a Keithley 4200 parameter analyzer.

\section{Results and discussion}

3.1 Syntheses and Characterization: The synthesis route of dithienylbenzothiadiazole based D-A-D materials with different end capping groups is outlined in Scheme 1. First, dithienylbenzothiadiazole (93\% yield) was synthesized using commercially available 4,7-dibromobenzo[c][1,2,5]thiadiazole and 2tributylstannylthiophene in dry $N, N$-dimethylformamide (DMF) in presence of tetrakistriphenyl phopshine palladium $\left[\mathrm{Pd}\left(\mathrm{PPh}_{3}\right)_{4}\right]$ catalyst at $80^{\circ} \mathrm{C}$ for $24 \mathrm{~h}$ by Stille coupling. Bromination of dithienylbenzothiadiazole was carried out using NBS in DMF at room temperature for $24 \mathrm{~h}$ producing 4, 7bis(5-bromothiophene-2-yl) benzothiadiazole (1) (62\% yield). This dibromo derivative (Compound 1) was used as a common block for synthesizing other two final compounds. Molecular organic semiconductors 4,7-bis(5-(4-butoxyphenyl)thiophen-2-yl)benzo[c][1,2,5]thiadiazole (BOP-TBT) and 4,7-bis(5-(4trifluoromethly)phenyl)thiophen-2-yl)benzo[c][1,2,5]thiadiazole (TFP-TBT) were synthesized using 4(butoxyphenyl) boronic acid and 4-(trifluoromethyl)phenyl)boronic acid with common compound $\mathbf{1}$ reacting in Schlenk flask with $\mathrm{Pd}\left(\mathrm{PPh}_{3}\right)_{4}$ catalyst in toluene/2 $\mathrm{M} \mathrm{K}_{2} \mathrm{CO}_{3}$ solvent mixture at $80^{\circ} \mathrm{C}$ under argon atmosphere for $72 \mathrm{~h}$ via Suzuki coupling respectively. After completion of the reaction, the resulting mixture was poured into a methanol and stirred for few hours to precipitate out the final crude compound. Both crude compounds BOP-TBT and TFP-TBT were then subjected to purification in temperature zone sublimation unit under vacuum at $280^{\circ} \mathrm{C}$. The pure compound was finally collected as a red crystalline 
solid and needles from the thin glass tube. The structure and purity of all compounds were confirmed by elemental analysis and MALDI-TOF respectively. The respective MALDI-TOF of compounds BOP-TBT and TFP-TBT are shown in Figure 1. Due to restrained solubility of these organic semiconductors in organic solvents, we were unable to measure the ${ }^{1} \mathrm{H}$ and ${ }^{13} \mathrm{C}$ NMR spectra.

3.2 Optical Properties: The absorbance and photoluminescence (PL) spectra of the BOP-TBT and TFPTBT measured in chloroform using $10^{-5} \mathrm{M}$ solutions and which are shown in Figure 1a and $1 \mathrm{~b}$ respectively. Both materials exhibits two absorption peaks attributed to thiophene constituent (lower wavelength region) and the charge transfer associated with thiophene-benzothiadiazole moieties (higher wavelength region) in the D-A-D backbone. In the lower wavelength region BOP-TBT and TFP-TBT exhibited absorption maxima at $352 \mathrm{~nm}$ and $341 \mathrm{~nm}$ respectively. In the longer wavelength region, BOP-TBT exhibits an absorption maximum at $504 \mathrm{~nm}$ whereas that for TFP-TBT is at $475 \mathrm{~nm}$. Although the conjugated backbone of both materials having similar conjugated blocks still the $29 \mathrm{~nm}$ and $11 \mathrm{~nm}$ of blue shift in longer and shorter wavelength region observed in TFP-TBT compared to BOP-TBT respectively which is attributed to the stabilization of the LUMO by the electron-withdrawing trifluoromethyl group. Similar observations have also been reported recently for pyridine-benzothiadiazole based co-oligomers. ${ }^{36}$ The optical band gaps calculated from the absorption cut off values are $2.06 \mathrm{eV}$ and $2.25 \mathrm{eV}$ for BOP-TBT and TFP-TBT respectively. The fluorescence spectra of BOP-TBT and TFP-TBT exhibit red PL maxima at $615 \mathrm{~nm}$ and $574 \mathrm{~nm}$ respectively. A blue shift of $41 \mathrm{~nm}$ is observed for TFP-TBT compared to BOP-TBT which is again related to the stabilization of LUMO due to electron withdrawing trifluoromethyl end capping group. $111 \mathrm{~nm}$ and $99 \mathrm{~nm}$ of the Stoke shift were observed for BOP-TBT and TFP-TBT respectively. This result clearly indicates that although possessing similar conjugated blocks incorporated in the backbone, the different alkyl end capping groups play a significant role in modulating photophysical properties.

\subsection{Electrochemical Properties: The electrochemical properties of BOP-TBT and TFP-TBT were} investigated by cyclic voltammetry in order to estimate the electrochemical band gaps and HOMO/LUMO energy levels as a function of the end capping groups. All CV measurements were recorded at room temperature in dichloromethane (compounds were sparingly soluble in DCM in order to measure the redox behaviour) using a conventional three electrode configuration consisting of a platinum wire working electrode, a gold counter electrode, and an $\mathrm{Ag} / \mathrm{AgCl}$ reference electrode under argon using tetrabutylamoniunm hexafluorophosphate as an electrolyte at a scan rate of $50 \mathrm{mV} / \mathrm{s}$. Both compounds exhibited reversible anodic and cathodic redox waves. HOMO-LUMO energy levels and the corresponding electrochemical band gaps of BOP-TBT and TFP-TBT were calculated from oxidation-reduction onset potentials. These onset potentials were converted to SCE (saturated calomel electrode) and the corresponding ionization potential (IP) and electron affinity (EA) values were derived from the onset redox potentials, based on $-4.4 \mathrm{eV}$ as the $\mathrm{SCE}$ energy level relative to vacuum $\left(\mathrm{EA}=\mathrm{E}_{\text {red-onset }}+4.4 \mathrm{eV}, \mathrm{IP}=\mathrm{E}_{\text {ox- }}\right.$ 
${ }_{\text {onset }}+4.4 \mathrm{eV}$ ). The CV curves for BOP-TBT and TFP-TBT are shown in Figure 3. Compound BOP-TBT clearly exhibits two dominant oxidation peaks arising from two electron donating thiophene blocks whereas only one reduction peak is observed which is due to single benzothiadiazole units incorporated in D-A-D backbone. Compound TFP-TBT also shows one strong and one weak oxidation peak whereas there are two reduction peaks due to benzothiadiazole (strong peak) and trifluoromethyl group (weak peak). The oxidation onsets for BOP-TBT and TFP-TBT were observed at $0.8 \mathrm{~V}$ and $1.10 \mathrm{~V}$ respectively. The HOMO values calculated for BOP-TBT and TFP-TBT are $5.20 \mathrm{eV}$ and $5.50 \mathrm{eV}$ while the LUMO values were determined to be $3.25 \mathrm{eV}$ and $3.62 \mathrm{eV}$ calculated from the reduction onsets. The $0.30 \mathrm{eV}$ and $0.37 \mathrm{eV}$ lowering of HOMO and LUMO values of TFP-TBT is due to the electron withdrawing effect of trifluoromethyl group. From these values it can be clearly seen that how HOMO-LUMO levels can be altered by using appropriate end capping groups, despite of having the same conjugated backbone. Electrochemical band gaps calculated for BOP-TBT and TFP-TBT from the HOMO-LUMO differences are $1.95 \mathrm{eV}$ and $1.88 \mathrm{eV}$ respectively. These values are found to be in good agreement with the optical band gaps calculated from the UV-vis absorption onset.

3.4 Thermal Analysis: In order to determine the thermal stability and thermal transitions of these compounds, thermogravimetric analysis (TGA) and differential scanning calroimetry (DSC) were conducted under a nitrogen flow. TGA measures the amount and rate of change in the weight of a material as a function of temperature or time in a controlled atmosphere. Both BOP-TBT and TFP-TBT compounds show a $5 \%$ weight loss (high decomposition temperature) at $400^{\circ} \mathrm{C}$ and $330^{\circ} \mathrm{C}$, respectively, as shown in Figure 4. This clearly indicates excellent thermal stability of the materials. Such a high stability is prerequisite for the purification of insoluble organic semiconductor using vacuum sublimation method at high temperature. The high thermal stability of these compounds is due to rigid backbone. Such thermally stable compounds allow fabrication of the devices via vacuum sublimation without any decomposition.

BOP-TBT shows better thermal stability than TFP-TBT due to the longer alkyl chain (butoxy) substituted on the phenyl ring compare to shorter alkyl chain (trifluoromethyl). This has been also confirmed by a derivative weight loss curves for both compounds where the weight loss is most apparent. The DSC scans of BOP-TBT and TFP-TBT are depicted in Figure 5 and this curve exhibits melting points at $222^{\circ} \mathrm{C}$ and $236^{\circ} \mathrm{C}$ respectively. BOP-TBT exhibits slightly lower melting temperature than TFP-TBT which is due to the longer alkyl chain (butoxy) substituted on the phenyl.

3.5 DFT Electronic Structure Calculation: In order to study the planarity of the materials and the effects of end capping groups on electronic properties, density functional theory (DFT) calculations of their electronic state were performed at the level of GGA-PW91-dspp/dnp using DMol ${ }^{3}$ module in the Materials Studio Modelling (MSM) software package (Accelrys Inc.). The optimized geometries and electron density isocontours of HOMO and LUMO of BOP-TBT and TFP-TBT with their torsion angles (between central D-A-D segment and alkyl substituted phenylene end capped groups) are shown in Figure 6. All the 
isocontour values are 0.02 atomic unit (a. u.). In all materials, the HOMOs and LUMOs are localized along the conjugated backbone. Such localization of the HOMO/LUMO orbital on such conjugated blocks has been commonly observed in previous theoretical studies. ${ }^{31}$ The theoretical calculated HOMO-LUMO values and the band gaps of BOP-TBT and TFP-TBT are comparable with the experimental results and exhibiting a similar trend (CV and optical data). The attachment of trifluoromethyl an electron withdrawing group to pheneylene causes the lowering of HOMO and LUMO of the TFP-TBT compared to BOP-TBT in spite of having similar conjugated backbone. Such trends are expected due to higher electro negativity/electron affinity of the trifluoromethyl group compared to butoxy group attached to the pheneylene unit. The theoretically predicted HOMO and LUMO energy levels are about 0.51 to $0.73 \mathrm{eV}$ higher than experimentally calculated values. The observed discrepancy of experimental and theoretical values are related with various effects such as effect of electrolyte, effect of solvent and conformational order in bulk state which is not taken into account in theoretical calculations. In order to confirm the effect of end capping groups on HOMO-LUMO shifting of BOP-TBT and TFP-TBT, we also studied molecular modelling on individual trifluoromethyl-phenylene and butoxy-phenylene end groups attached to thiophene. The optimized geometries and electron density isocontours at Isovalue 0.01 and 0.03 of HOMO and LUMO of trifluoromethyl-phenylene and butoxy-phenylene moieties attached to thiophene end groups are shown in Figure 7. The HOMO and LUMO values for butoxy-phenylene thiophene end group are calculated as $-4.917 \mathrm{eV}$ and $-1.718 \mathrm{eV}$, whereas for trifluoromethyl-phenylene thiophene these values are $5.759 \mathrm{eV}$ and $-2.583 \mathrm{eV}$ respectively. Just by changing electron donating butoxy group by electron withdrawing trifluoromethyl group, LUMO value has been shifted by $0.87 \mathrm{eV}$. This theoretical data is significant to check the experimental results and we believe that theoretical modelling is useful tool for designing and synthesizing novel electron transporting organic semiconductors.

3.6 OFET Characteristics: The electrical properties of BOP-TBT and TFP-TBT were investigated by fabricating and characterizing OFET devices using thin film of BOP-TBT and TFP-TBT. A bottom gate top-contact OFET device configuration was used to characterize the charge transport properties of BOPTBT and TFP-TBT. The devices were fabricated on an either $\mathrm{p}+-\mathrm{Si}$ (or $\mathrm{n}+-\mathrm{Si}) \mathrm{n}^{+}$-doped silicon wafers with a thermally grown silicon oxide layer $(\sim 200 \mathrm{~nm})$ having a capacitance of $\sim 17 \mathrm{nF} / \mathrm{cm}^{2}$. The $+-\mathrm{Si}$ or $\mathrm{n}+-$ Si served as the gate electrode while the silicon oxide layer acted as the gate dielectric. The BOP-TBT and TFP-TBT were deposited on $\mathrm{Si} / \mathrm{SiO}_{2}$ substrate by vacuum deposition method. Gold is used as a source and drain electrodes and were thermally evaporated on top of the organic semiconductor thin film using a shadow mask. OFET devices have a channel length $(L)$ of $100 \mu \mathrm{m}$ and a channel width $(W)$ of $1 \mathrm{~mm}$. The evaluation of transistor performance was carried out in a glove box under nitrogen using a Keithley 4200 SCS semiconductor characterization system. The output and transfer characteristics of OFETs using BOPTBT and TFP-TBT channel semiconductor are shown in Figure 8. The carrier mobility in the saturated regime, $\mu_{\text {sat }}$, is calculated according to equation (1): 
$\mathrm{I}_{\mathrm{SD}}=\mathrm{C}_{\mathrm{i}} \mu_{\mathrm{sat}}(\mathrm{W} / 2 \mathrm{~L})\left(\mathrm{V}_{\mathrm{G}}-\mathrm{V}_{\mathrm{T}}\right)^{2}$

where $\mathrm{I}_{\mathrm{SD}}$ is the drain current, $W$ and $L$ are, respectively, the semiconductor channel width and length, $\mathrm{C}_{\mathrm{i}}$ is the capacitance per unit area of the gate dielectric, and $\mathrm{V}_{\mathrm{G}}$ and $\mathrm{V}_{\mathrm{T}}$ are, respectively, the gate voltage and threshold voltage. $\mathrm{V}_{\mathrm{T}}$ of the device was determined from linear extrapolation of the linear fit of $\left(\mathrm{I}_{\mathrm{SD}}\right)^{1 / 2} \mathrm{vs}$ $V_{G}$ curve in the saturation regime at $I_{D}=0$. The BOP-TBT based devices show $p$ - channel performance with the best calculated hole mobility of $0.02 \mathrm{~cm}^{2} / \mathrm{V}$-s and threshold voltage of -33.0 Volts. The OFET devices fabricated on OTS treated $\mathrm{Si}_{/} \mathrm{SiO}_{2}$ substrates have shown two orders of magnitude higher hole mobility as compared to the transistors fabricated on bare $\mathrm{Si}_{2} / \mathrm{SiO}_{2}$ substrates $\left(\mu_{\mathrm{h}}=6.2 \times 10^{-4} \mathrm{~cm}^{2} / \mathrm{V}\right.$-sec.). Higher hole mobility exhibited in OFET devices fabricated on OTS treated substrates can be attributed to better packing of BOP-TBT thin films on SAM treated substrates. This mobility values are within the range of previously reported thiophene-benzothiadiazole based D-A-D small molecules. ${ }^{27,}{ }^{30,}{ }^{31}$ Lower mobility of BOP-TBT compared to our earlier reported thiophene-benzothiadiazole based small molecules T4B1 ${ }^{30}$ is might be due to the weak D-A interaction induced by phenylene moiety (weak donor) than thiophene (strong donor). When the TFP-TBT molecule, was used as a channel semiconductor in OFET devices, $\mathrm{n}$-channel performance was observed with the best electron mobility $0.004 \mathrm{~cm}^{2} / \mathrm{Vs}$ with threshold voltage 45.0 Volts calculated from the saturation regime. Both the small molecules have similar conjugated backbone with the only difference being in the alkyl group substituted on phenylene group. Due to the electron withdrawing trifluoromethyl group substitution on phenylene ring in TFP-TBT, the LUMO is lowered and it results in n-channel performance whereas BOP-TBT having butoxy group on phenylene shows p-channel performance. There are several reports of discrete p-channel and n-channel organic semiconductors but there are very few reports of making both $\mathrm{p}$ and $\mathrm{n}$-channel organic semiconductors using straightforward synthesis approach using similar conjugated backbone and just by tuning alkyl chain substitution. From these observations it is clear that the different end capping group substitution is an effective synthetic method for the generation of potential $\mathrm{p}$ and $\mathrm{n}$-channel semiconductors for high mobility OFET devices.

\section{Conclusions}

Donor-acceptor-donor (D-A-D) based conjugated molecules BOP-TBT and TFP-TBT using thiophenebenzothiadiazole-thiophene central core with butoxy phenyl and trifluoromethyl phenyl end capping groups have been designed, synthesized and characterized. Both small molecules have shown optical band gaps ranging from 2.06-2.25 eV. HOMO and LUMO energy levels are calculated to be in the range of 5.15 -5.4 $\mathrm{eV}$ to 3.25.-3.62 eV from $\mathrm{CV}$ measurements. Upon testing both materials for OFETs, trifloromethyl phenyl end capped material shows n-channel whereas butoxy phenyl end capped material shows p-channel behavior. Vaccum processed OFETs of BOP-TBT and TFP-TBT have shown maximum hole mobility of $0.02 \mathrm{~cm}^{2} / \mathrm{Vs}$ and electron mobility of $4 \times 10^{-3} \mathrm{~cm}^{2} / \mathrm{Vs}$, respectively. keeping similar central D-A-D 
conjugated segment and just by tuning end capping groups gives both $\mathrm{p}$ and $\mathrm{n}$ - channel organic semiconductors in a single step using straightforward synthesis.

\section{Acknowledgements}

The authors acknowledge the Visiting Investigatorship Program (VIP) of the Agency for Science, Technology and Research (A*STAR), Republic of Singapore for financial support.

\section{References}

[1] Y. Shirota, H. Kageyama, Chem. Rev.,2007, 107, 953.

[2] M. T. Lloyd, J. E. Anthony, G. G. Malliaras, Mater. Today, 2007, 10, 34.

[3] F. Garnier, Acc. of Chem. Res., 1999, 32, 209.

[4] M. Mas-Torrent, C. Rovira, Chem. Soc. Rev., 2008, 37, 827.

[5] S. Allard, M. Forster, B. Souharce, H. Thiem, U. Scherf, Angew. Chem. Int. Ed., 2008, 47, 4070;

[6] H. Klauk, Ed. Wiley-VCH, Organic Electronics: Materials, Manufacturing and Applications, Weinheim, Germany, 2006.

[7] K. Müllen and G. Wegner, Electronic Materials: The Oligomer Approach, Wiley-VCH, Weinheim, Germany, 1998.

[8] H. E. Katz , A. J. Lovinger, C. Klock, T. Siegrist, W. Li, Y. Y. Lin, A. Dodabalapur, Nature, 2000, 404, 478.

[9] B. Crone, A . Dodabalapur, Y. Y. Lin, R. W. Filas, A. LaDuca, R. Sarpeshkar, H. E. Katz, W. Li, Nature, 2000, 403, 521.

[10] B. Yoo, B. A. Jones, D. Basu, D.Fine, T. Jung, S. Mohapatra, A. Facchetti, K. Dimmler, M. R. Wasielewski, T. J. Marks, A. Dodabalapur, Adv. Mat., 2007, 19, 4028.

[11] M. H. Yoon, S. A. DiBenedetto, A. Facchetti, T. J. Marks, J. Am. Chem. Soc., 2005, 127, 1348

[12] A. Facchetti, Y. Deng, A. C. Wang, Y. Koide, H. Sirringhaus, T. J. Marks, R. H. Friend, Angew. Chem. Int. Ed., 2000, 39, 4547.

[13] J. A. Letizia, A. Facchetti, C. L. Stern, M. A. Ratner, T. J. Marks, J. Am. Chem. Soc., 2005, 127, 13476; 
[14] S. Ando, R. Murakami, J. Nishida, H. Tada, Y. Inoue, S. Tokito, Y. Yamashita, J. Am. Chem. Soc., 2005, 127, 14996;

[15] K. Ito, T. Suzuki, Y. Sakamoto, D. Kubota, Y. Inoue, F. Sato, S. Tokito, Angew. Chem. Int. Ed., 2003, 42, 10;

[16] C. D. Dimitrakopoulos, P. R. L. Malenfant, Adv. Mater., 2002, 14, 99;

[17] D. J. Gundlach, Y. -Y Lin, T. N. Jackson, S. F. Nelson, D. G. Schlom, IEEE Electron Device Lett., 1997, 18, 87.

[18] H. E. Katz, Z. Bao, S. L. Gilat, Acc. Chem. Res., 2001, 34, 359.

[19] F. Garnier, A. Yassar, R. Hajlaoui, G. Horowitz, F. Deloffre, B. Servet, S. Ries, P. Alnot, J. Am. Chem. Soc., 1993, 115, 8716.

[20] D. J. Gundlach, Y.-Y. Lin, T. N. Jackson, D. G. Schlom, Appl. Phys. Lett., 1997, 71, 3853.

[21] Z. Bao, A. J. Lovinger, J. Brown, J. Am. Chem. Soc., 1998, 120, 207.

[22] M. M. Shi, H. Z. Chen, J. Z. Sun, J. Ye, M. Wang, Chem. Comm., 2003, 14, 1710.

[23] Y. Sakamoto, T. Suzuki, M. Kobayashi, Y. Gao, Y. Fukai, Y. Inoue, F. Sato, S. Tokito, J. Am. Chem. Soc., 2004, 126, 8138.

[24] C. Di, J. Li, G. Yu, Y. Xiao, Y. Guo, Y. Liu, X. Qian, D. Zhu, Org. Lett., 2008, 10, 3025.

[25] M. Mass-Torrent, C. Rovira, Chem. Soc. Rev., 2008, 37, 827.

[26] C. R. Newman, C. D. Frisbie, D. A. da. S. Filho, J. L. Bredas, P. C. Ewbank, K. R. Mann, Chem. Mater., 2004, 16, 4436.

[27] Y .Yamashita, Sci. Technol. Adv. Mater., 2009, 10, 024313.

[28] B. Walker, A. B. Tamayo, X.-D. Dang, P. Zalar, J. H. Seo, A. Garcia, M. Tantiwiwat and T.-Q. Nguyen, Adv. Funct. Mat., 2009, 19, 3063;

[29] J. A. Kong, E. Lim, K. K. Lee, S. Lee, S. H. Kim, Sol. Energy. Mat. Sol. Cells., 2010, 94, 2057.

[30] P. Sonar, S. P. Singh, S. Sudhakar, A. Dodabalapur, A. Sellinger, Chem. Mater., 2008, 9, 3184;

[31] P. Sonar, S. P. Singh, P. Leclère, M. Surin, R. Lazzaroni, T. T. Lin, A. Dodabalapur, A. Sellinger, J. Mat. Chem., 2009, 19, 3228.

[32] P. Sonar, S. G. Santamaria, T. T. Lin, A. Sellinger, H. Bolink, Aust. J. Chem., 2012, http://dx.doi.org/10.1071/CH12171.

[33] T. Kono, D. Kumaki, J. i. Nishida, T. Sakanoue, M. Kakita, H. Tada, S. Tokito, Y. Yamashita, Chem. Mater. 2007, 19, 1218. 
[34] G. Myhre, A. Sayyad, S. Mataka, S. Pau, Appl. Phys. Lett. 2011, 99, 091108.

[35] J. Huang, Y. Xu, Q. Hou, W. Yang, M. Yuan, Y. Cao, Macromol. Rapid Commun. 2002, 23, 709.

[36] M. Akhtaruzzaman, M. Tomura, J. Nishida and Y. Yamashita, J. Org. Chem., 2004, 69, 2953. 

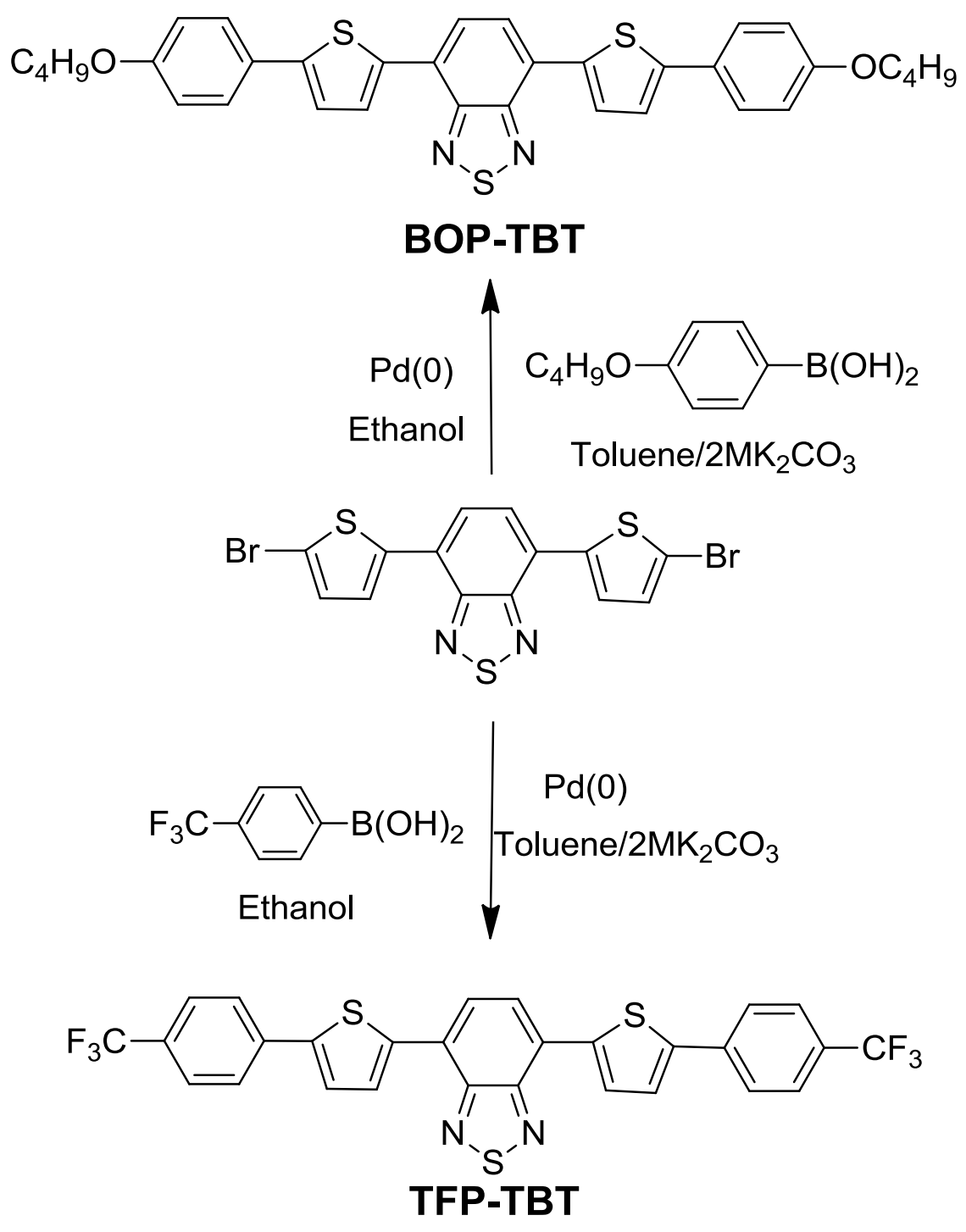

Scheme 1. Synthesis of D-A-D organic semiconductors BOP-TBT and TFP-TBT for OFETs 
(a)

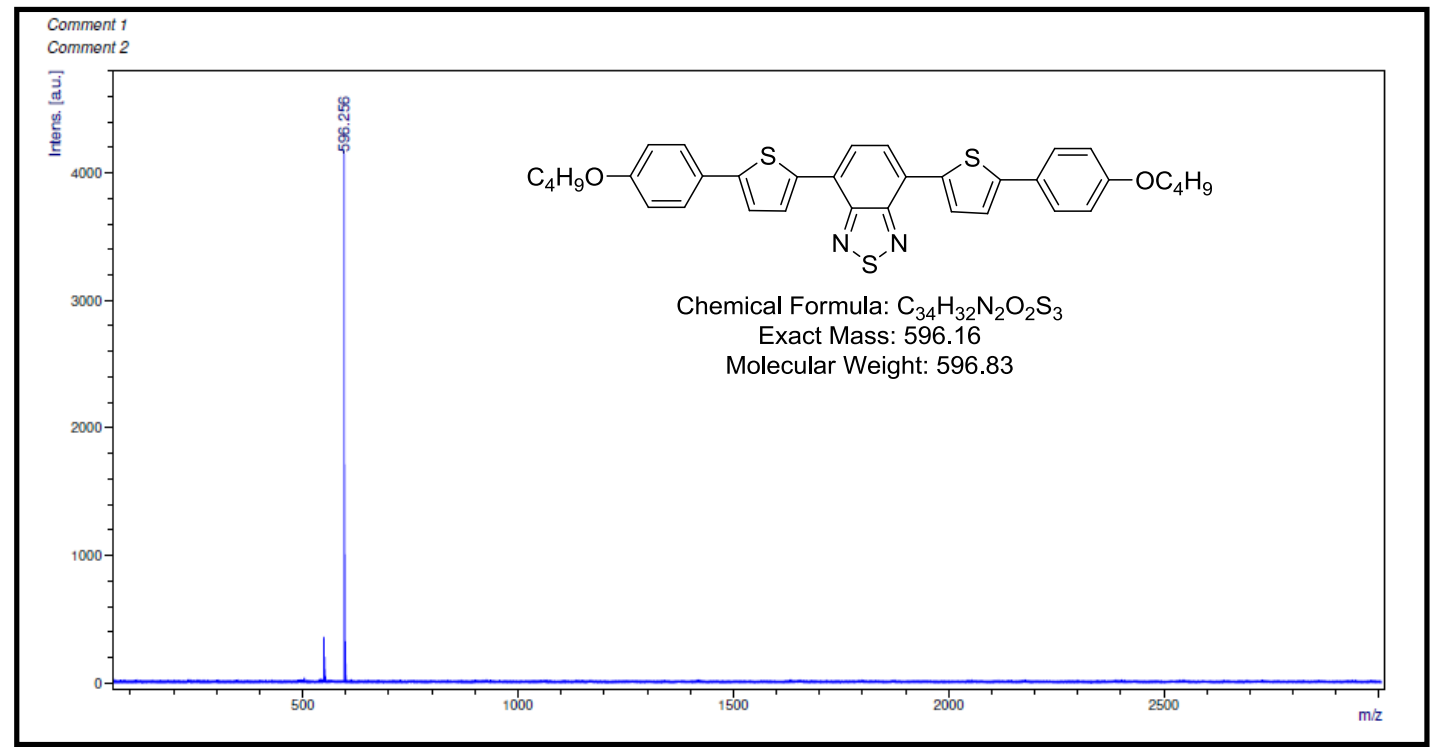

(b)

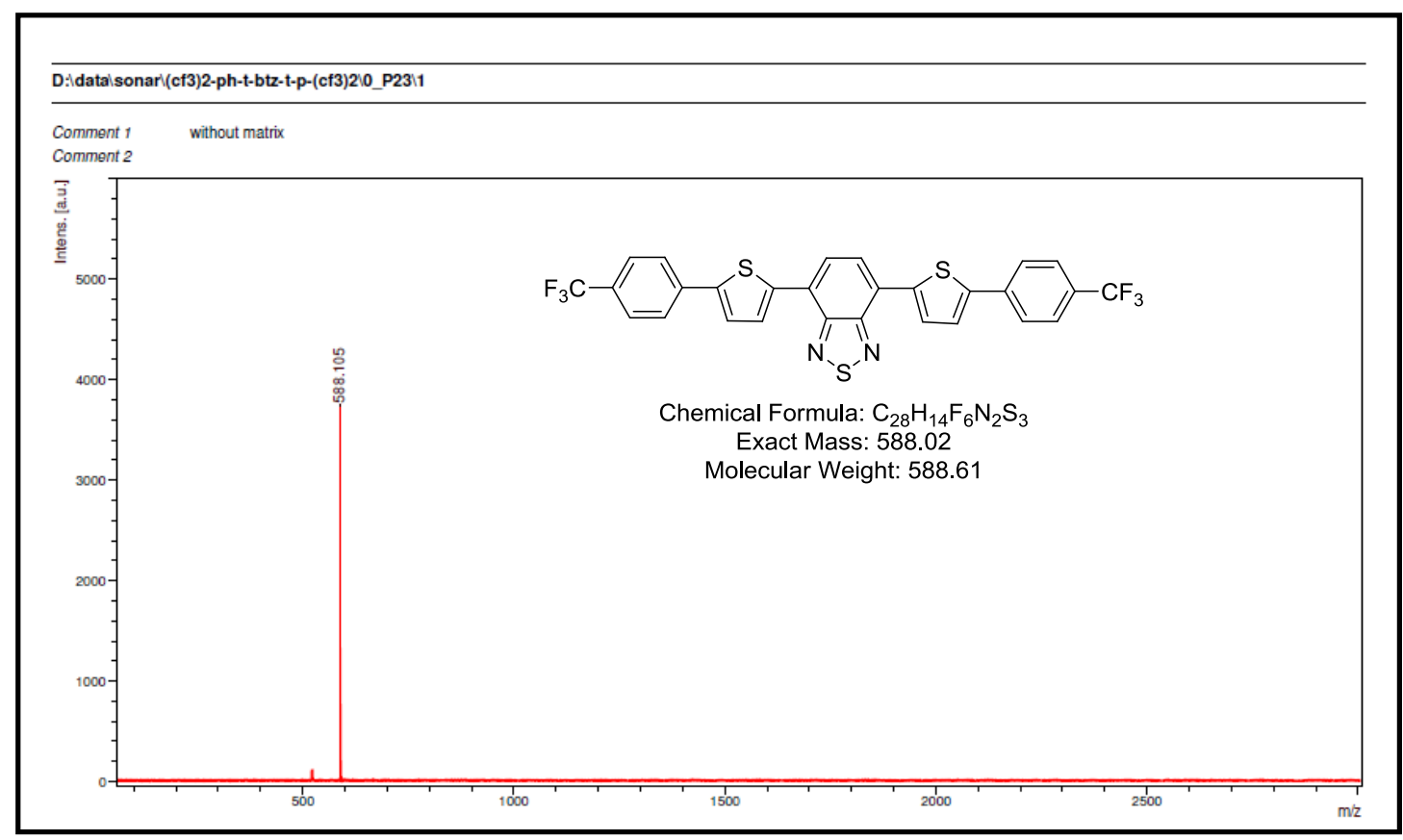

Figure 1. MALDI-TOF (Matrix assisted laser desorption/ionization time-of-flight) spectra of BOP-TBT and TFP-TBT organic semiconductors. 
(a)

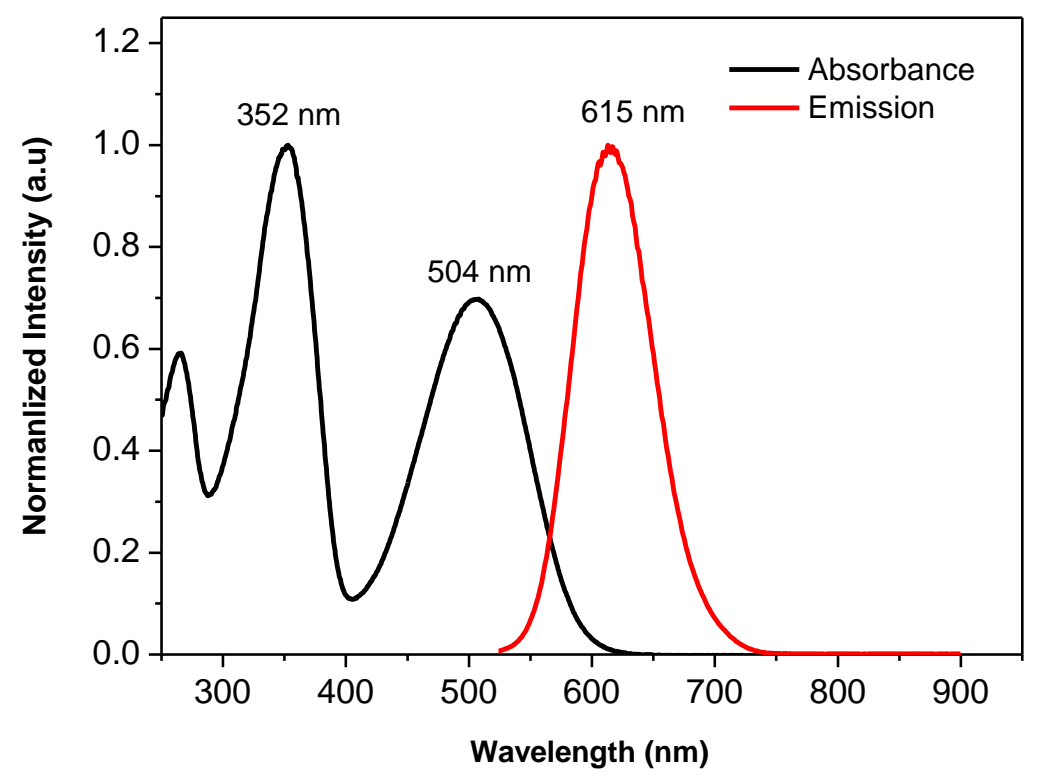

(b)

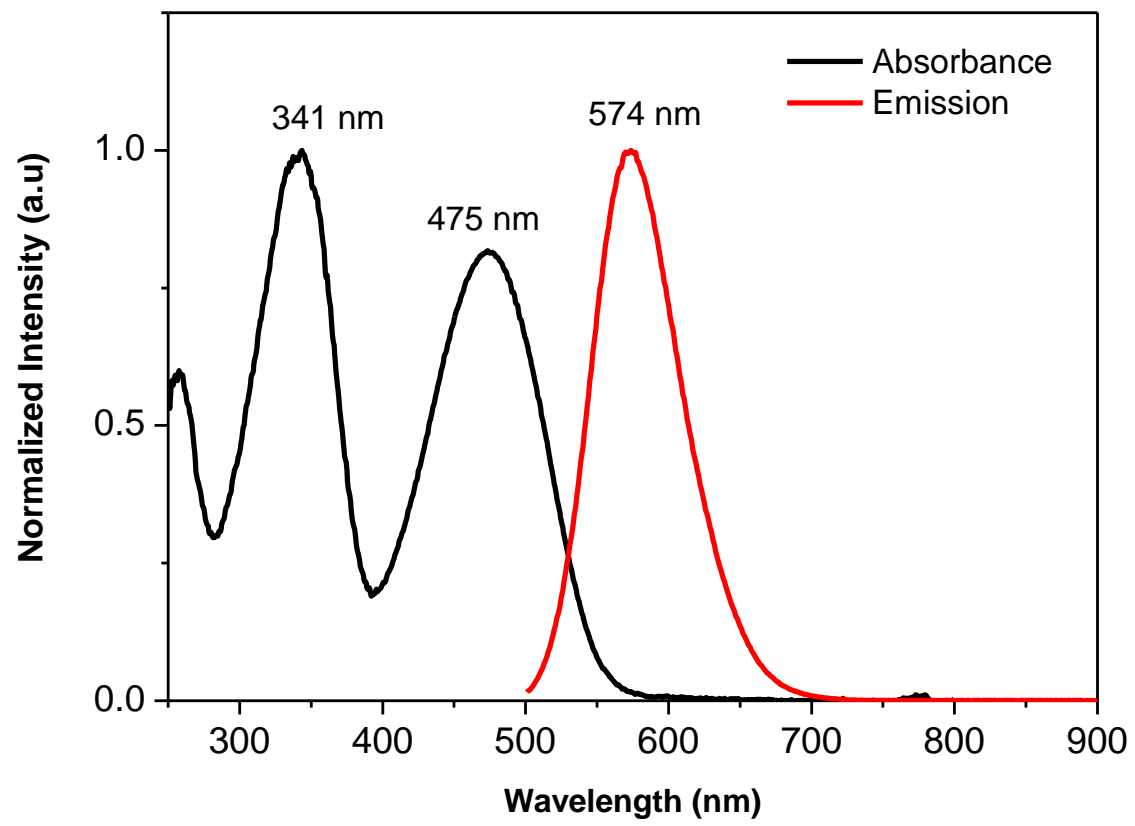

Figure 2. Absorbance and emission spectrum of (a) BOP-TBT and (b) TFP-TBT D-A-D organic semiconductors. 
(a)
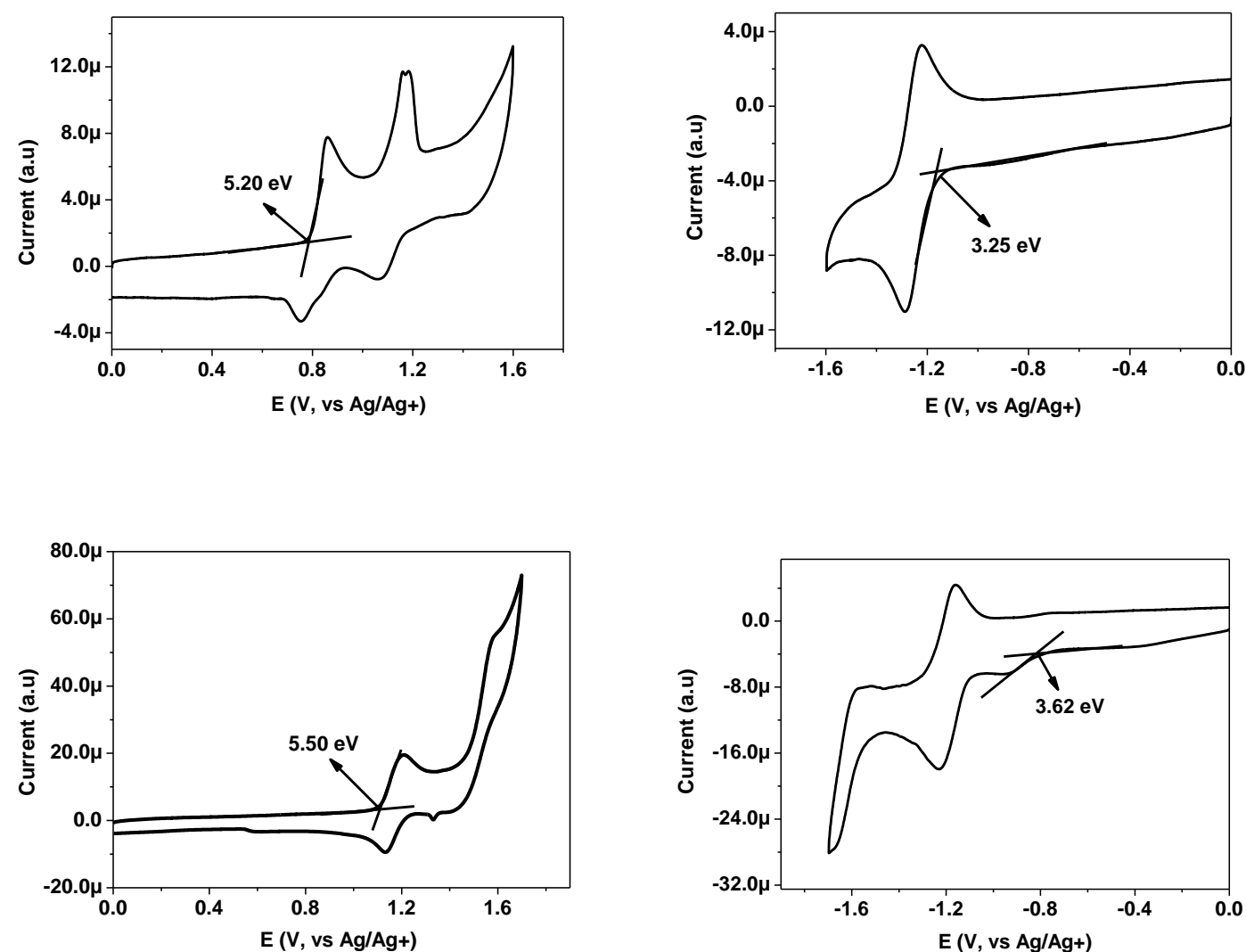

Figure 3. CV (cyclic voltammogram) analysis of (a) BOP-TBT and (b) TFP-TBT D-A-D organic semiconductors. 
(a)

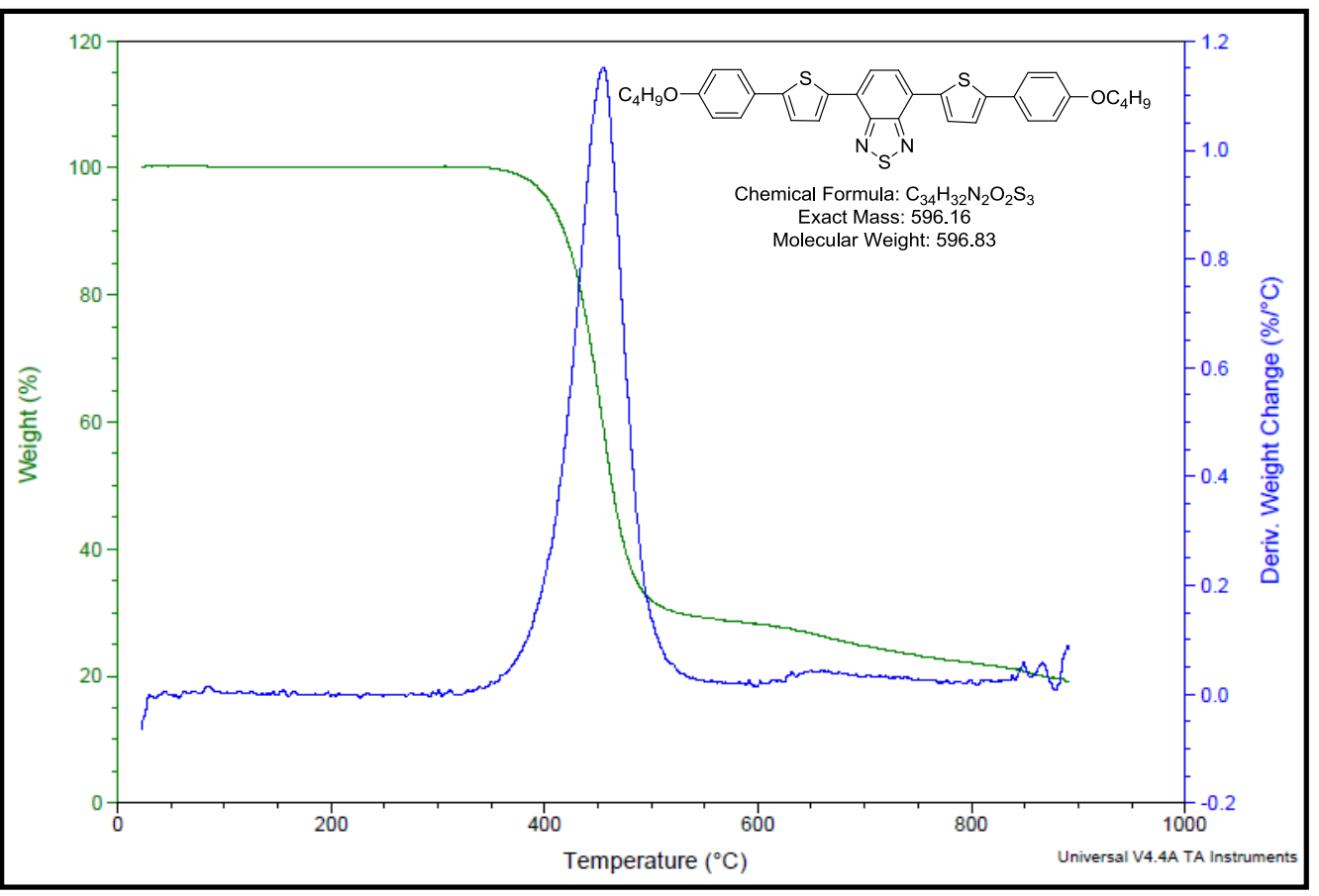

(b)

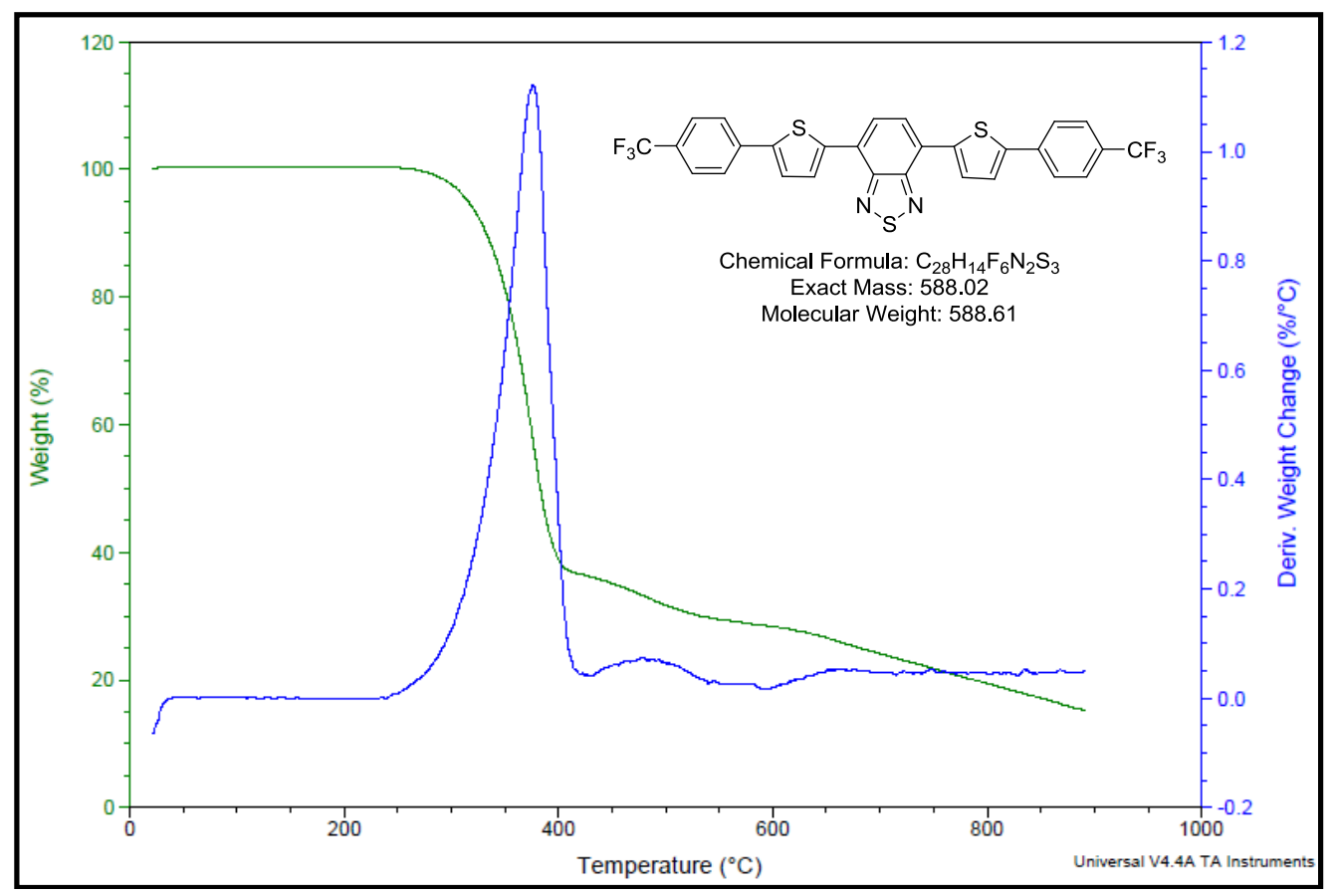

Figure 4. Thermogravimetric analysis (TGA) of (a) BOP-TBT and (b) TFP-TBT D-A-D organic semiconductors. 
(a)

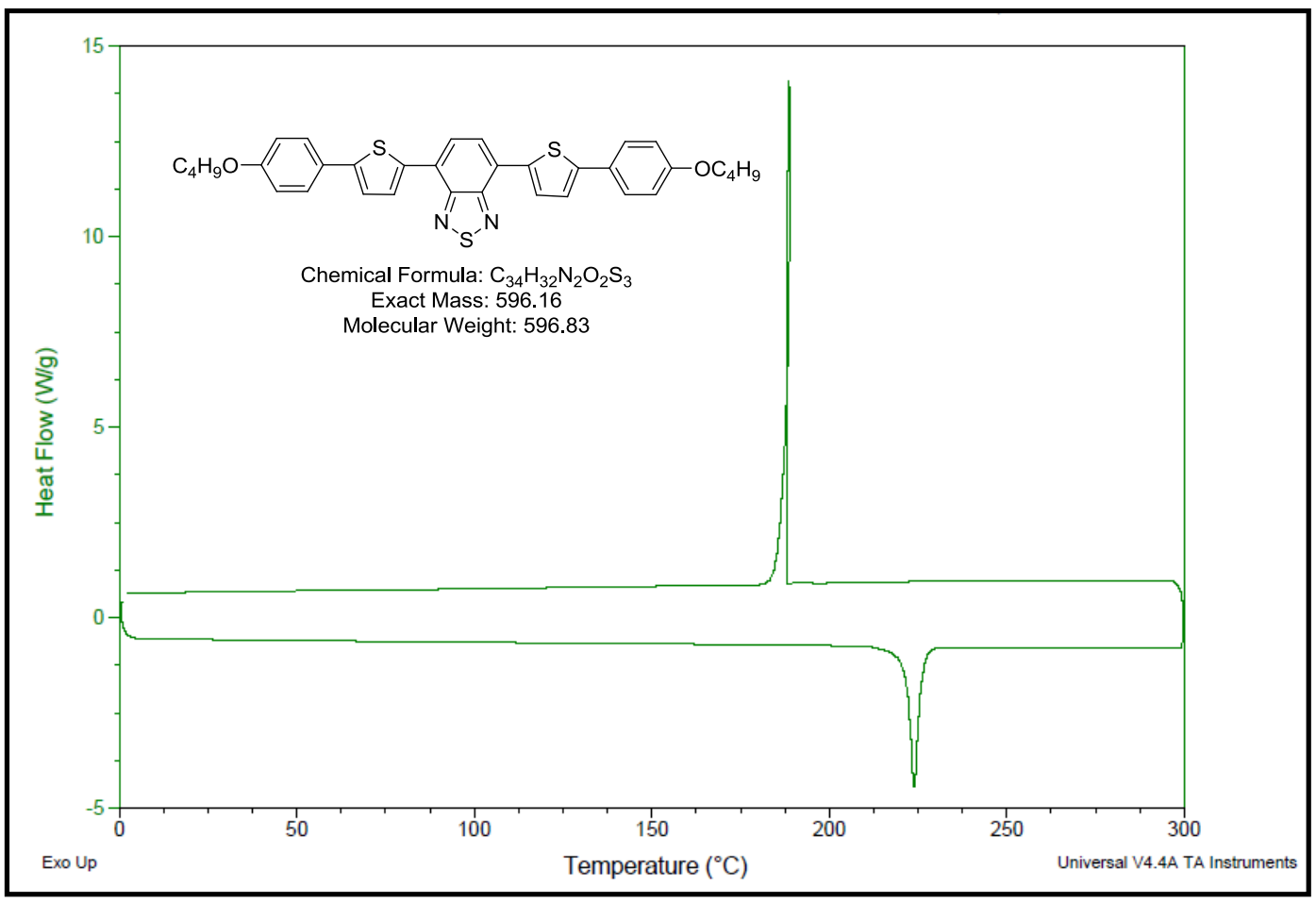

(b)

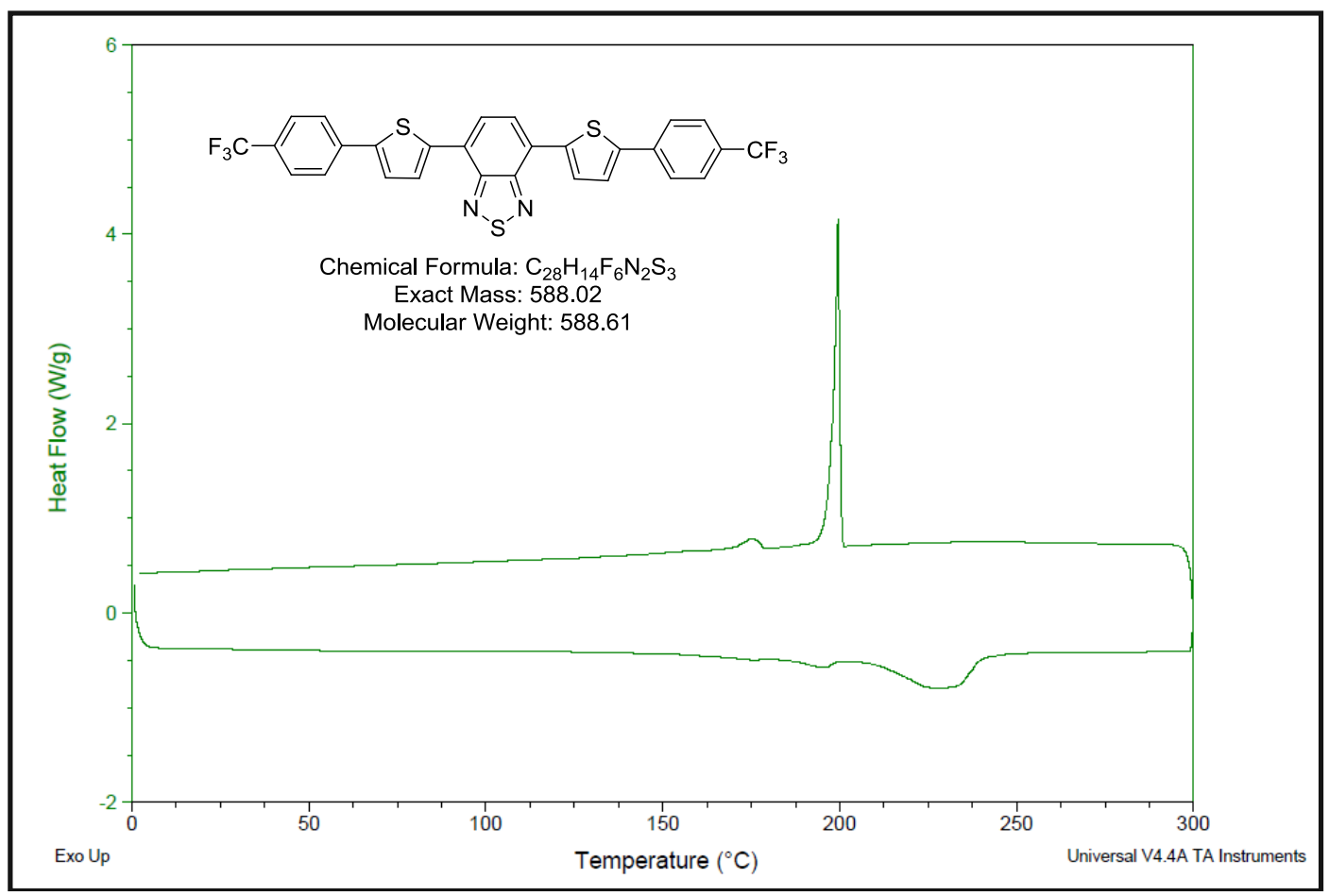

Figure 5. Differential Scanning Calorimetry (DSC) thermograms of (a) BOP-TBT and (b) TFP-TBT DA-D organic semiconductors. 
(a)

Optimized Geometry

HOMO

LUMO
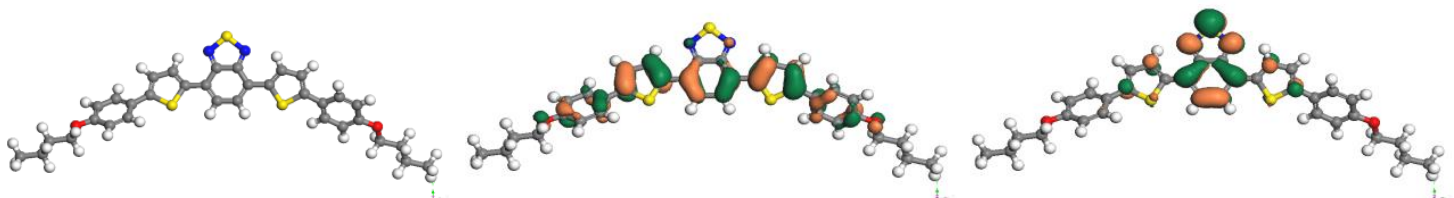

BOP-TBT

$-4.602$

$-3.288$
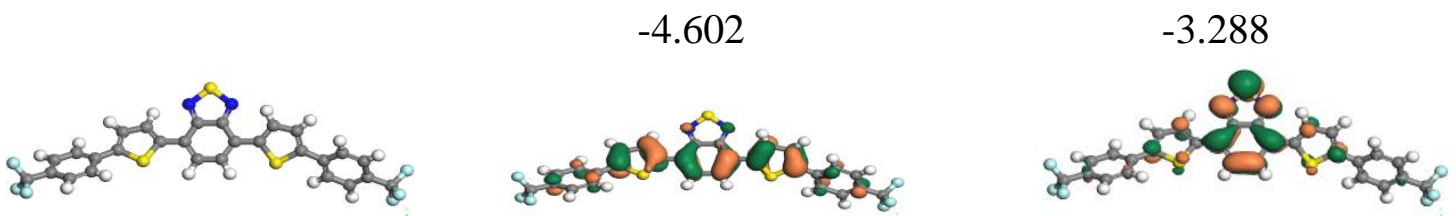

DFP-TBT

$-5.336$

$-3.796$

(b)
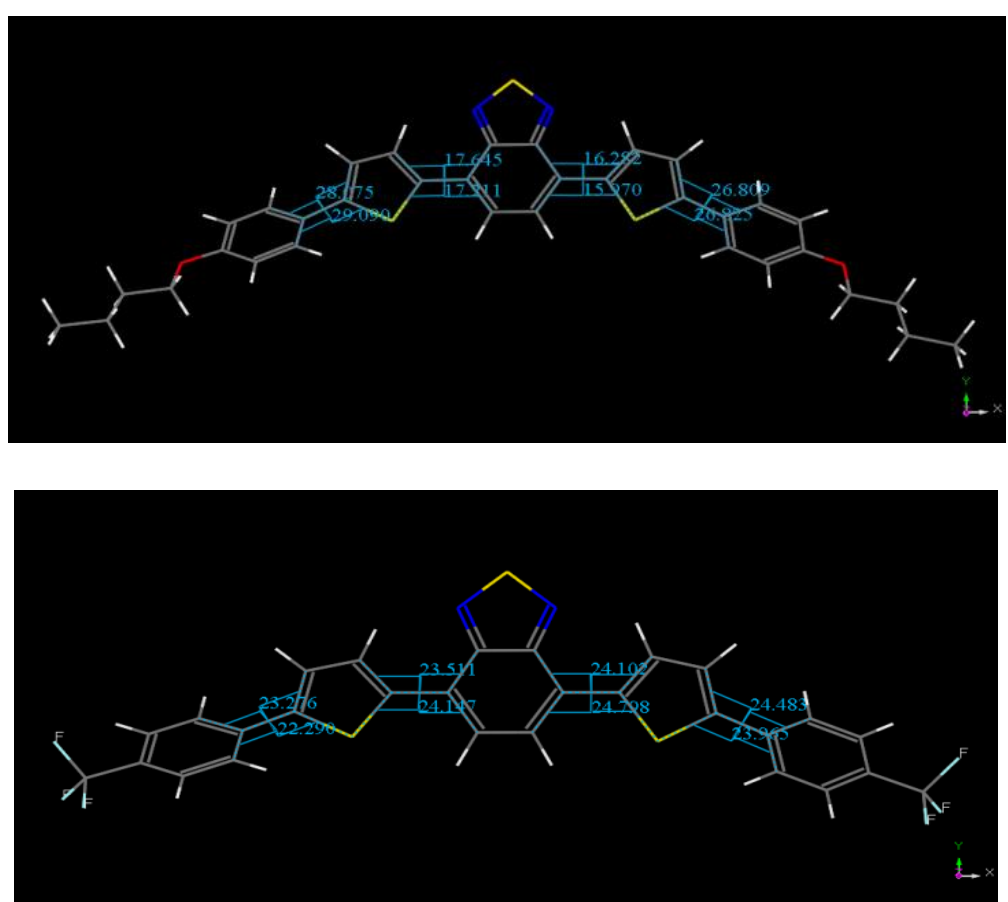

Figure 6. The optimized geometries (a) and electron density isocontours of HOMO and LUMO of BOPTBT and TFP-TBT and (b) the torsion angles between central D-A-D segment and alkyl substituted phenylene end capped group for the optimized structures obtained at GGA-PW91-dspp/dnp level and quality "fine" using $\mathrm{DMol}^{3}$ code. 
(a)
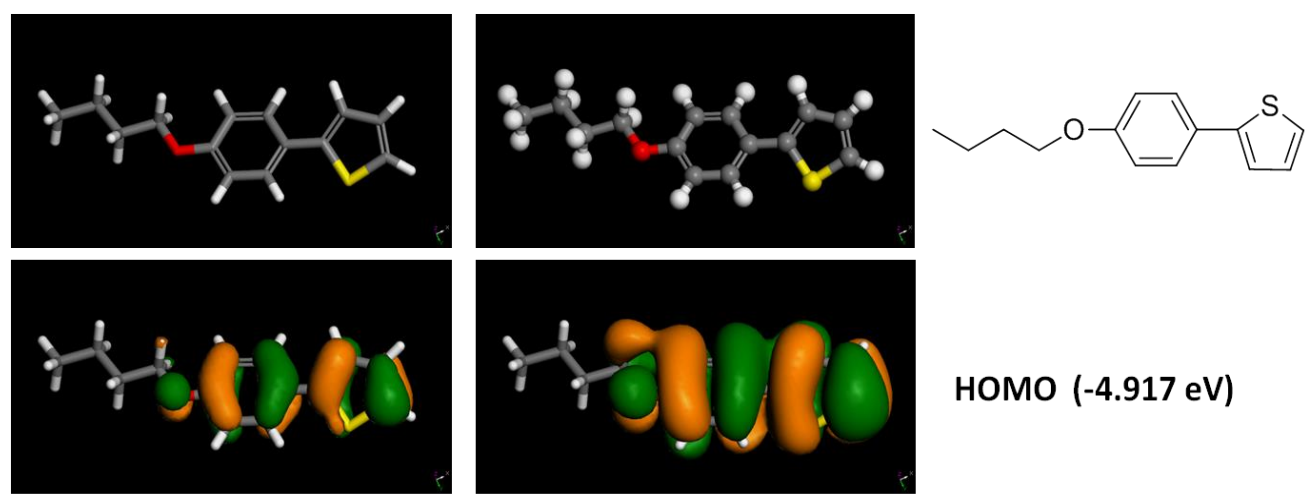

HOMO (-4.917 eV)
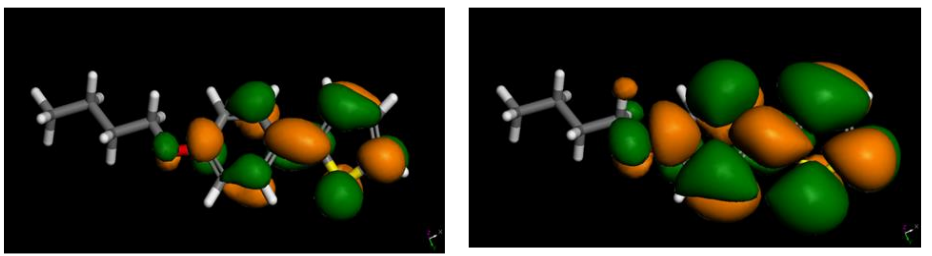

LUMO (-1.718 eV)

Isovalue $=0.03$

Isovalue $=0.01$

(b)
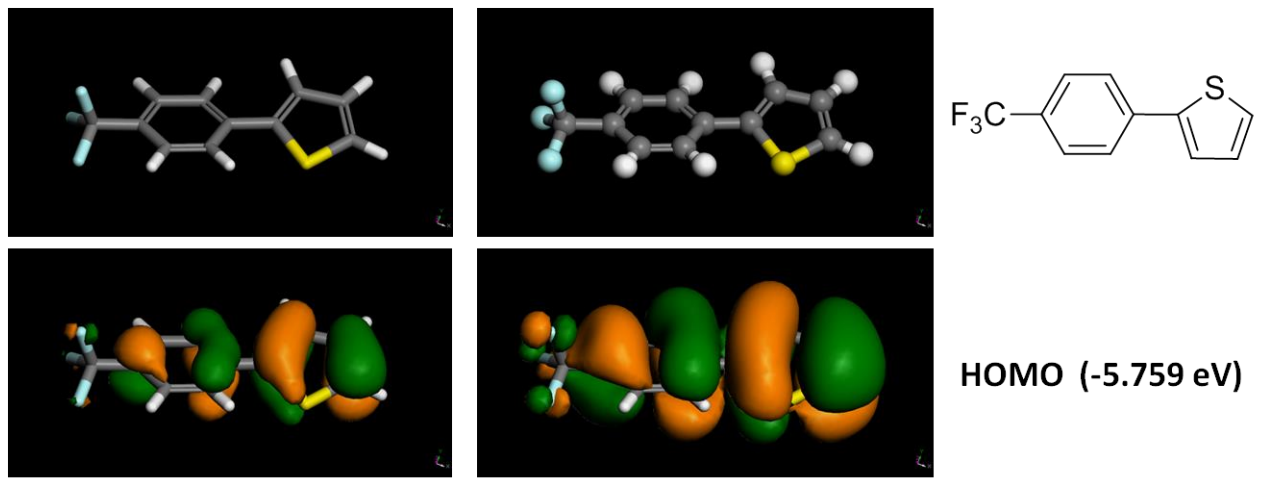

HOMO (-5.759 eV)

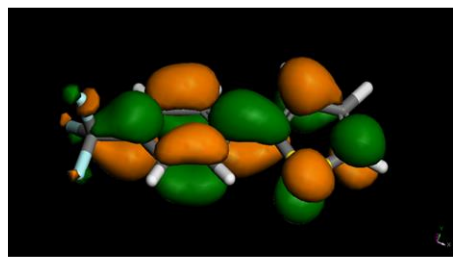

Isovalue $=0.03$

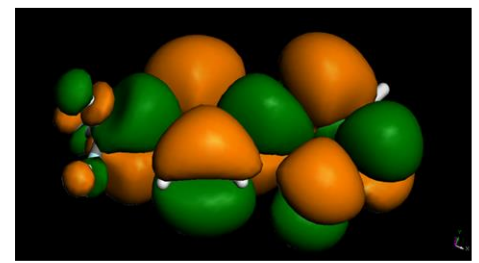

Isovalue $=0.01$

\author{
(-5.759 eV)
}

LUMO $(-2.583 \mathrm{eV})$

Figure 7. The optimized geometries and electron density isocontours of HOMO and LUMO (measured at Isovalue $=0.03$ and 0.01 ) of end capping groups (a) butoxy- phenyl and (b) trifluoro-phenyl used for synthesizing BOP-TBT and TFP-TBT respectively. These values are obtained at GGA-PW91-dspp/dnp level and quality "fine" using $\mathrm{DMol}^{3}$ code. 

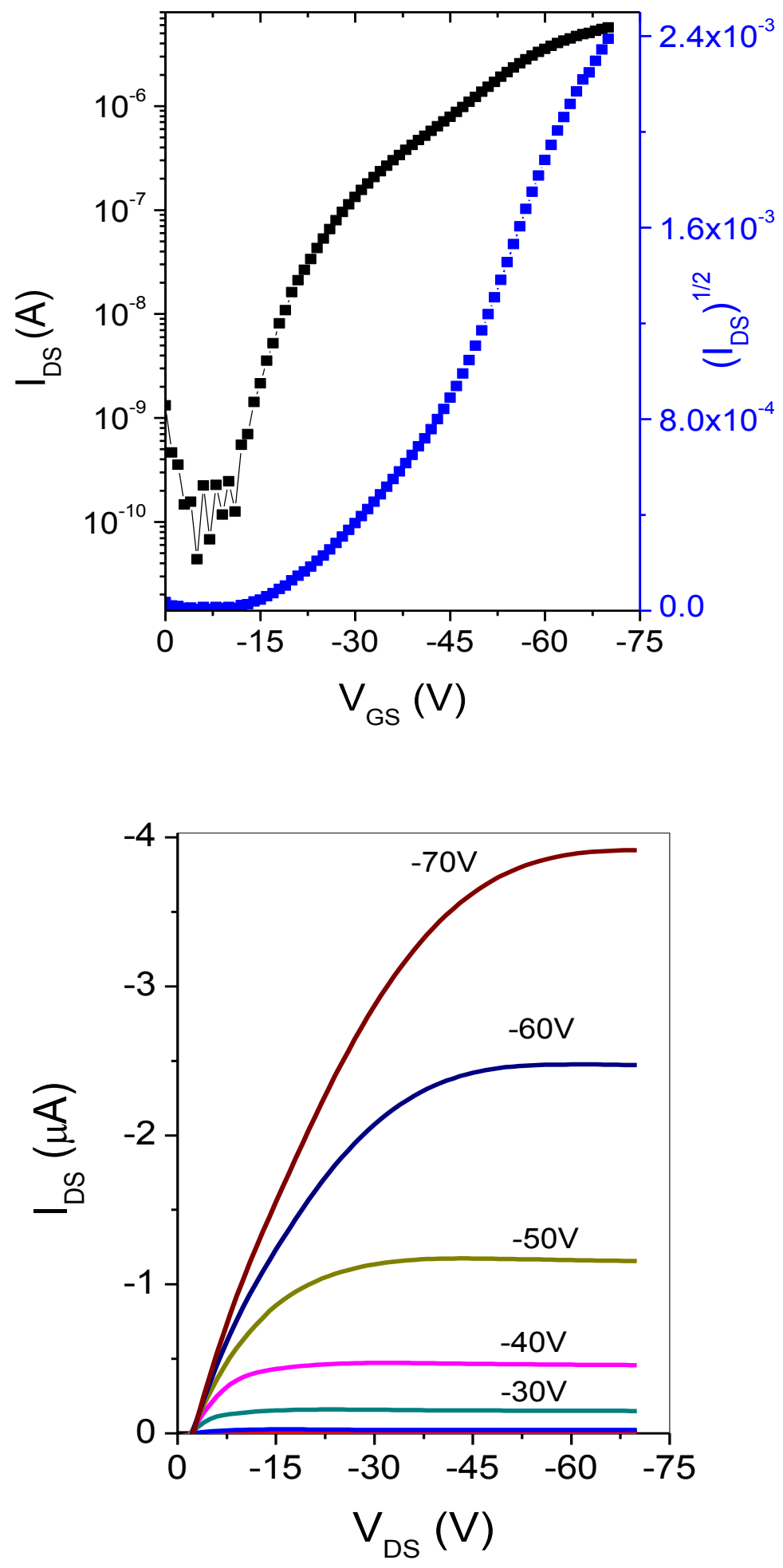

Figure 8. Transfer ( $V_{G S}$ vs. $\left.I_{D S}\right)$ and output ( $V_{D S}$ vs. $\left.I_{D S}\right)$ characteristics of BOP-TBT based OFET $(\mathrm{L}=100 \mu \mathrm{m} ; \mathrm{W}=1 \mathrm{~mm})$ on OTS treated $\mathrm{p}+-\mathrm{Si} / \mathrm{SiO} 2$ substrate devices. 

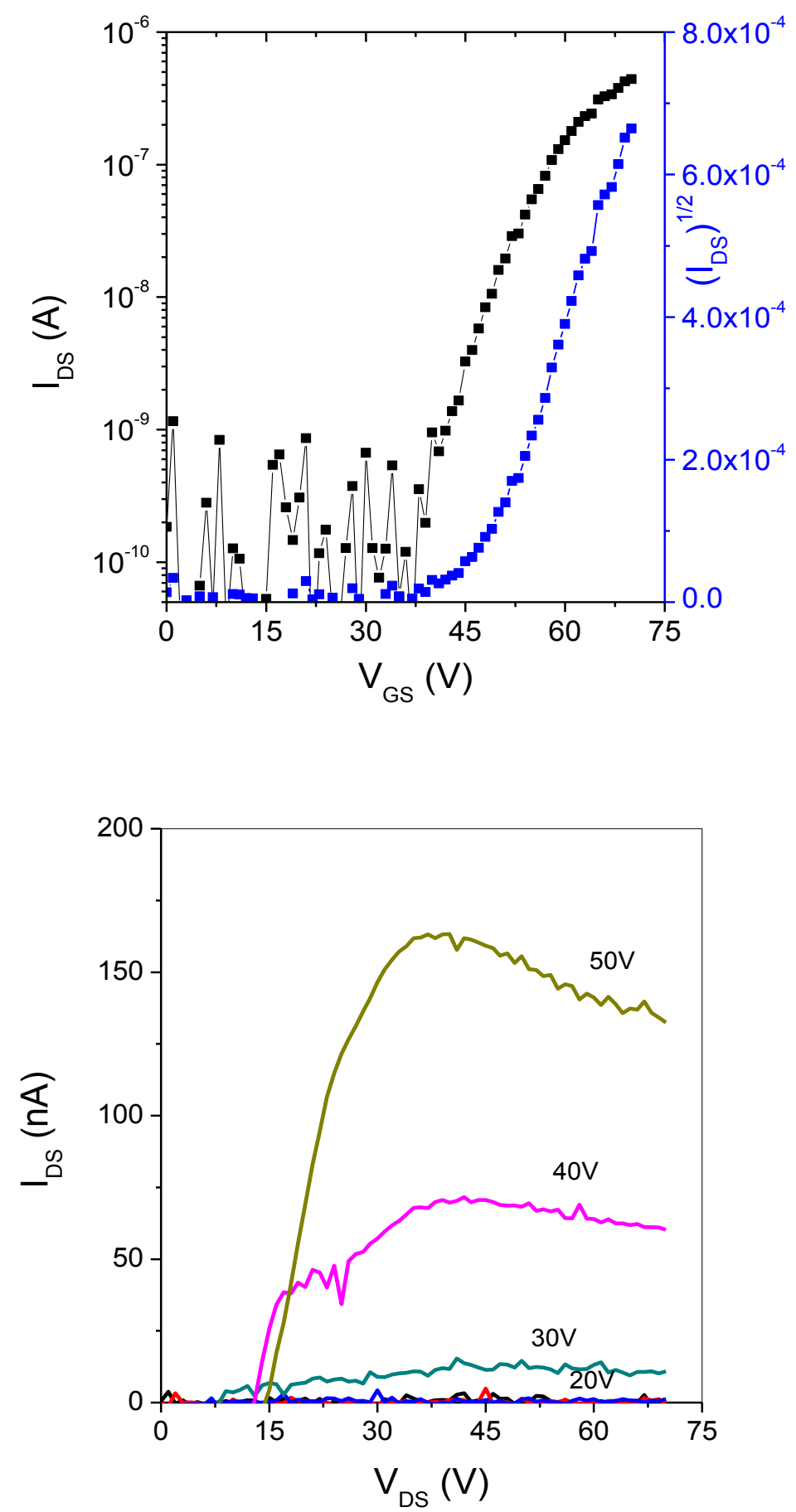

Figure. 9 Transfer ( $V_{\mathrm{GS}}$ vs. $\left.I_{\mathrm{DS}}\right)$ and output ( $V_{\mathrm{DS}}$ vs. $\left.I_{\mathrm{DS}}\right)$ characteristics of TFP-TBT based OFET $(L=100$ $\mu \mathrm{m} ; W=1 \mathrm{~mm}$ ) on OTS treated $\mathrm{p}+-\mathrm{Si} / \mathrm{SiO}_{2}$ substrate devices. 
Dithienylbenzothiadiazole Based Donor-acceptor-donor (D-A-D) based conjugated molecules using thiophene Donor-acceptor Organic benzothidiazole-thiophene central core Semiconductors and Effect of End with trifluoromethyl phenyl and butoxy Capping Groups on Organic Field phenyl end capping groups were Capping Groups on Organic Field Effect Transistor (OFET) Performance

Prashant Sonar*, Samarendra P Singh, Ting-Ting Lin, Ananth Dodabalapur* synthesized by Suzuki coupling. Both materials were tested in OFET device geometries and shows $\mathrm{p}$ and n-channel behavior with respect to different end capping groups. The highest hole and electron mobilities for both materials were calculated $2 \times 10^{-2} \mathrm{~cm}^{2} / \mathrm{Vs}$ and $4 \times 10^{-3}$ $\mathrm{cm}^{2} / \mathrm{Vs}$ respectively using top contact geometry.

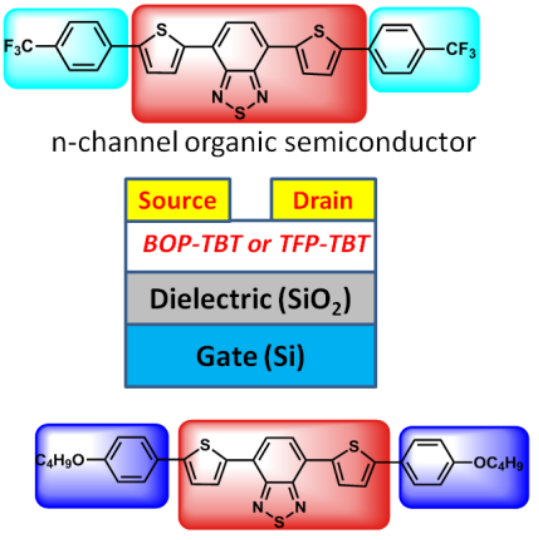

p-channel organic semiconductor 